\title{
Participatory Governance in Smart Cities: the urbanAPI case study
}

\section{Kamran Soomro', Zaheer Khan', David Ludlow²}

${ }^{1}$ Centre for Complex Cooperative Systems, Department of Computer Science and Creative Technologies, Faculty of Environment and Technology, Unversity of the West of England, Bristol, UWE.

${ }^{2}$ Centre for Sustainable Planning and Environments, Department of Architecture and the Built Environment, Faculty of Environment and Technology, Unversity of the West of England, Bristol, UWE.

\{kamran.soomro, zaheer2.khan, david.ludlow\}@uwe.ac.uk

\begin{abstract}
This paper presents some results from an EU FP7 RTD project urbanAPI, in which three ICT applications target different aspects of participatory urban governance. The 3D Scenario Creator allows urban planners to visualise urban development proposals in 3 dimensions, share them with different stakeholders and obtain their feedback. The Mobility Explorer allows urban land use and transport planners to visualise and analyse population distribution and mobility patterns in the city. Finally, the Urban Development Simulator simulates socio-economic activity in response to alternative planning scenarios. These urbanAPI ICT applications are implemented in four pilot cities; Vienna (Austria), Vitoria-Gasteiz (Spain), Bologna (Italy) and Ruse (Bulgaria), and evaluated with respect to their various requirements. Results show that the applications are useful tools, enhancing spatial planning assessements, and enabling public participation, communicating proposed plans to different stakeholders and identifying key development issues which can provide crucial inputs in planning and decision making processes.
\end{abstract}

Keywords: smart cities, participatory governance, co-production

Reference to this paper should be made as follows: Soomro, K., Khan, Z. and Ludlow, D. (2016) 'Participatory Governance in Smart Cities: the urbanAPI case study', Int. J. of Service Technology and Management, ???????

\section{Biographical notes:}

Kamran Soomro is a Research Associate in the Faculty of Environment and Technology at the University of the West of England. He holds $\mathrm{PhD}$ in Computer Science and has over 7 years experience in research and academia. His research interests include use of ICT technologies for smart cities and urban management, knowledge management and artificial intelligence. His expertise also includes distributed systems such as grid and clouds. He been involved in the EU FP7 neuGRID, urbanAPI and DECUMANUS projects in which he was responsible for managing software requirements and evaluation.

Zaheer Khan holds Bachelor's, Master's and PhD degrees in Computer Science. He has over 14 years of experience in academic research and teaching. His research interests are use of ICT solutions for smart cities and urban management. He is 
leading the IT for Smart Cities unit of the Centre for Complex Cooperative Systems (CCCS) and he is a member of the Software Engineering Research Group (SERG) in UWE, Bristol. His expertise lies in the application of the state-of-the-art technologies from distributed computing, clouds, sensor web, software engineering, business process management, data management and software agents in multi-disciplinary application domains.

David Ludlow is an urban planner with substantial practice experience gained in UK government spatial planning agencies, and subsequently as EU research project manager at UWE, responsible for securing and managing more than 50 EU funded projects. These projects focus on smart city decision-making systems, integrated urban management information systems, and sustainable urban development. David is currently project manager for EU FP7 urbanAPI (Smart Cities ICT Call), DECUMANUS (Urban Planning Downstream Services, Space Call), urbanNexus (Urban Management, Environment Call), ESPON SEGI Applied Research project, and is urban planning expert for the European Topic Centre Spatial Information Analysis (European Environment Agency). David is a member of the EU Expert Group on the Urban Environment (European Sustainable Cities Project), and the Expert Group for the EU Thematic Strategy on the Urban Environment (6th Environment Action Programme).

\section{Introduction}

According to a 2013 report (ESPAS 2013), Europe will be 77\% urbanised by 2030, urbanisation on both global and EU scales that poses significant challenges for city administrations. Effective territorial decision-making is essential to support land use management and transport planning in addressing societal challenges associated with growing urbanisation, including the need for economically vital, socially cohesive, resource efficient and climate proof cities. The scale and complexity of these challenges is such that traditional approaches to governance, and particularly traditional approaches to public participation in urban planning are often characterised as restrictive and inefficient (Weber \& Khademian 2008).

In response "participatory governance" seeks to secure the engagement of all stakeholders in decision-making, deploying innovative Information and Communication Technologies (ICT) to provide unique opportunities for participatory governance of smart cities, offering benefits including more effective governance, combined with enhanced legitimacy and justice (Khan, Ludlow, et al. 2014; Khan, Kiani, et al. 2014; Khan et al. 2015; Fung 2015).

In this context a central research question concerns "which ways ICT tools can most effectively contribute to stakeholder engagement in smart city participatory governance?" In addressing this research question this paper explores the involvement of stakeholders through user-driven innovation and collaborative

The Global Economy in 2030: Trends and Strategies for Europe [Last accessed: 06/11/2015, http: / / europa.eu/espas/pdf/espas-report-economy.pdf] 
design and leveraging these processes to achieve desired outcomes. The paper presents some results from the EU FP7 urbanAPI project, the prime purpose of which was to support the development of ICT-enabled participatory planning and city governance. In addressing this research concern the project adopted a predominantly top-down perspective appropriate to the development of tools and methodologies supporting neighbourhood development, city-wide mobility and city-region evolution. Accordingly key stakeholders included municipal land use planners with expertise in both local as well as strategic plan development and implementation. These stakeholders were fully familiar with the varied context of land-use plan development and implementation in which these tools and methodologies would need to be effectively applied.

Accordingly this focus of stakeholder engagement did not directly include the wider diversity of that community, including for example, citizens, civic society and business community organisations. This wider community is characteristic of recent conceptions of the essential ecosystem frameworks for co-production and co-design of urban plans, as well as the design and development of associated ICT enabled applications.

The project developed three applications: 3D Scenario Creator at neighbourhood level, Mobility Explorer at city-wide level, and Urban Development Simulator at city-region scale. In order to evaluate the effectiveness and usefulness of these applications, they were implemented in four pilot cities; Vienna, Vitoria-Gasteiz, Bologna and Ruse. In this paper the results of the user evaluation are presented and discussed with a view to analysing the extent to which the three applications identified above fulfil the requirements of the partner cities (Khan, Ludlow \& Loibl 2013).

The structure of this paper is as follows: Section 2 presents related work. In Section 3, an overview of the urbanAPI project and its applications is provided, followed by elaboration of the evaluation methodology in Section 3.5. The pilot cities and their needs are introduced in Section 4 followed by the evaluation results in Section 5 . Finally, the paper offers a critical reflection of the applications developed in Section 6, followed by conclusions in Section 7.

\section{Related Work}

ICT tools and applications have developed rapidly and in a variety of ways including direct democratic experiments such as planning cells, public assessment exercises and moderated discussions of various kinds, as well as experiments with the science/policy interface and impact assessment (Liberatore \& Funtowicz 2003; Boyd \& Chan 2002a). Citizens have incorporated a number of roles in these experiments including active and participative, critical in the oversight of politics and administration, productive in generating data useful for assessing public services and efficient in co-producing public services. While this is clearly a 
demanding set of roles, there is evidence that participatory decision-making in the framework of urban governance initiatives has the potential to widen and deepen democratic decision-making and public service delivery (Wampler \& McNulty n.d.). According to some researchers, concepts attributed to "transformational governance" (Jacquier 2005; Weerakkody \& Dhillon 2008; Weerakkody et al. 2011) have also emerged in response to the specific demands for the delivery of holistic urban planning to secure sustainable urban development in which partnership is key. This perspective of transformational governance emphasises the essential need for traditional top-down expert-driven and sectorally defined urban planning to be combined with bottom-up processes of stakeholder engagement and partnership formation (Albrechts \& others 2010).

With rapid ICT innovations including Web 2.0/3.0, crowd sourcing, 3D interactive visualisation and simulation for past and future urban growth, ubiquitous access to the web through smart phones, availability of ambient environmental sensors and the Internet of Things, and computing and storage capacities using cloud computing, multi-way interaction for participatory governance is further enabled. Many ICTrelated planning and analysis tools have been developed helping citizens to understand decisions and the impacts of decisions by providing quantitative and visual outputs for development scenarios, providing access to decision polls or helping to explore citizens' behaviour to improve urban design and infrastructure (Boyd \& Chan 2002b). Similarly, many ICT applications have been developed for participatory urban planning, e.g. mobile phone 3D Augmented Reality application for Vienna (Lang \& Sittler 2012), Turku SoftGIS for Helsinki (Kahila \& Kyttä 2009; Kyttä 2011) and PME using mobile phone data (i.e. GSM data) for Vienna (Loibl \& Peters-Anders 2012). However, most of existing tools and applications are limited in their contribution to provision of rich and extensive interactive operations (i.e. editing, deleting or modifying scenarios) which can further support public participation in defining future urban models, thus, contributing towards policy development.

Recognizing the potential of ICT tools, local and national governments have started to share public data for transparency and control, citizen participation, development of new innovative products and governmental efficiency (Parycek \& Sachs 2010; The Open Government Working Group 2012). However, researchers (Janssen \& Zuiderwijk 2012) argue that while open data initiatives from local and national governments share public data, they require further investigation in adopting this data in planning, policymaking and public participation by introducing new mechanisms and transforming current processes. They also indicated that the major focus is on publishing the data, and there are no mechanisms and/or processes for public engagement to capture inputs for planning, policymaking and decisionmaking. This suggests that city administrations should identify new mechanisms or re-engineer current processes, as suggested by other researchers (Weerakkody et al. 2011) to utilise open data and promote public participation for greater benefit. 


\section{The urbanAPI project}

urbanAPI is a user-driven pan-European collaborative research project funded by the European Commission under the Seventh Framework Programme (FP7). The project is built upon the foundations of the EU smart cities agenda with a focus on on ICT enabled urban governance. urbanAPI aims to support decision making processes in urban land use planning by enhancing governance capabilities in respect of issue identification, policy analysis, consultation, and evaluation. The project focuses on three spatial dimensions, the neighbourhood, city-wide and city-regional scales by developing three applications consisting of neighbourhood 3D Scenario Creator (3DSC), citywide Motion Explorer (ME) and city-region Urban Development Simulation (UDS). Four European cities (Vienna, Bologna, Vitoria-Gasteiz and Ruse) participated in the project as pilot case studies for the development and implementation of the above applications. The stakeholders in the urbanAPI project consisted of various domain experts from these pilot cities including GIS experts and urban planners. There was also an informal stakeholder group consisting of domain experts from various organisations external to the project. They formed an advisory group that provided guidance and advice to the project partners. A detailed set of user requirements were acquired from the cities, specified according to urban planning scenarios, which identified user needs and requirements, forming essential criteria for the development of the tools and subsequent evaluation of the urbanAPI applications (Khan, Ludlow \& Loibl 2013). Table 1 depicts city participation in different urbanAPI applications, participation that was based on the local policy priorities. The various applications developed as part of the urbanAPI toolset are described subsequently.

\subsection{D Scenario Creator (3DSC)}

Using virtual reality or 3D applications for urban planning is not a new concept. For example, initial attempts were made in the late 1990s to show the benefits of interactive 3D applications for public participation in urban planning, and since then, many alternative applications have been developed (Doyle et al. 1998; Al-Kodmany 2002; Manoharan et al. 2002; Stellingwerff \& Kuhk 2004). However, a general challenge for such a work is how to create interactive 3D worlds (and other information technology [IT] policy support tools) with data collection, feedback and adopted steering mechanisms effectively, i.e. with verifiable impact and efficiently, i.e. with little effort (Hanzl 2007).

In the above context, the urbanAPI 3DSC application aims to visualise urban development plans with the help of 3D scenarios in order to support negotiation between various stakeholders in the decision-making process of urban development. Interactive control of planning interventions and real time visual presentation of the new effects created by changes in the urban plans help citizens to understand alternative development proposals, as well as interventions to more effectively meet their needs. The application supports aerial and ground perspectives for exploring these visual representations. Allowing interactive modifications of alternative 
proposals including building size, height, shape etc. helps stakeholders to understand the planning proposals, hence promoting bottom-up decision-making, policy development and plan implementation. The 3DSC application also provides the capability to process rich 3D models imported in different formats including CAD and GIS databases.

The 3DSC consists of three distinct components; the web interface, the Admin Tool and the Rule Editor. Each of these components fulfils a specific purpose. The Admin Tool is used to create the $3 \mathrm{D}$ models representing the planning proposals for which planners require feedback. Once the model has been created, it is uploaded to the web interface. This interface is publicly accessible and through it citizens and various other stakeholders can explore and evaluate the 3D models, and provide their feedback to the planners by annotating 3D web models. The Rule Editor is mainly a data pre-processing tool which allows construction of complex data processing chains using a visual interface. Planners can drag and drop various components that represent "steps" in these chains on a canvas. For example, in order to develop a planning proposal in 3D, the Admin Tool requires a 3D representation of the city to be available. The planners can then add or remove objects from that model. However, many cities do not have such 3D models available, in which case, planners can use the Rule Editor to extrapolate a 3D model from 2D data and metadata. Planners can also use the Rule Editor to apply a specific colour to objects possessing certain characteristics, e.g. specific metadata properties, shape, size etc.

\subsection{Mobility Explorer (ME)}

This application helps urban planners to acquire information and visualise the population mobility patterns associated with various land uses in the city (PetersAnders et al. 2014). In order to secure this intelligence on urban mobility the application utilises anonymised mobile phone location and usage data that is collected by mobile phone service providers (e.g. through GSM - Global System for Mobile communication). This information is effectively a portrayal of socio-economic activity in the city, and represents a vital source of information in helping planning agencies understand and manage public and private mobility in the urban envioment at various scales from local to city-wide, according to urban planning policy objectives. For example, visual display of movement patterns between specific urban districts during specific times (day/night) provide insights into mobility, as well as generate origin-destination matrices, that can provide mobility indicators for assessment of the effectiveness of urban transport planning policy.

\subsection{Urban Development Simulator (UDS)}

This application uses agent-based modelling to simulate the effects of planning decisions over a period of time, e.g. 20, 30, 40 years. It can be applied at local neighbourhood, city and city-region scales, assisting in understanding the consequences of complex spatial planning decisions over time. For example, simulation of socio-economic activity in response to the future expansion of the city. Interactive control of proposed planning interventions, to simulate alternative 
scenarios for the city expansion, and the associated impacts generated by these interventions, allows the public to engage in the planning process and enables participatory governance. Detailed and easily understandable information about planning decisions and full transparency about the expected impacts supports negotiation activities during the public participation process. Moreover, the application incorporates public preferences obtained via various questionnaires in simulating future scenarios.

\subsection{Development Methodology}

The urbanAPI project followed a structured development methodology as depicted in Figure 1. During the development of this project, end users comprising representatives of the respective cities were mainly involved in two phases; during the requirements definition and the evaluation phases. The methodology consisted of the following steps:

1. Requirements and Stakeholder Engagement: In this step end users comprising representatives of the pilot cities were consulted in order to better understand their needs and requirements. The CoReS methodology was followed in this phase of the project (Khan, Ludlow \& Loibl 2013). This methodology is a stepwise approach to the problem of defining requirements for a project in collaboration with the stakeholders. The first step is laying the groundwork and acquiring the necessary context. The second step is conducting requirements workshops with the stakeholders to define user scenarios for the project. Based on those scenarios specific requirements are extracted and finally those requirements are validated by the stakeholders. The Redmine system was used to manage and track requirements as well as consult the stakeholders (Sarkan et al. 2011).

2. Tool Design and Development: Once the requirements were identified, the design of the tools themselves was derived from these requirements. As a result, the three applications were defined using a Scrum-based agile methodology. Stakeholders were not involved in this phase of the project and it was conducted by the developers of the applications. However, the city representatives were available to respond to any questions or clarifications the developers might raise.

3. User and Technical Evaluation: Finally, user and technical evaluation of the developed products was performed. Technical evaluation was needed to test the quality of urbanAPI software using well defined software testing methodologies such as white box testing, test cases and unit tests. It was performed by the developers with the objective to ensure that urbanAPI applications do not fail when used by different stakeholders. After technical evaluation, the user evaluation focused on consulting with the end users and stakeholders from the pilot cities to obtain feedback regarding various aspects of the developed applications. An online portal hosting various questionnaires was developed using Drupal ${ }^{2}$. Details about the user evaluation conducted as well as the results

2 Drupal Content Management Sysem, https:/ / www.drupal.org [Last accessed 6 May, 2016] 
obtained are presented in Section 5. The impact of the tools is discussed in Section 6. This helped ensure that the applications met the specified stakeholder requirements.

The above applications were developed to deal with specific user scenarios and requirements of the case study cities (Khan, Ludlow \& Loibl 2013). A web-based unified user interface was developed using the Liferay portal (Agarwal 2015) and made available to stakeholders for beta testing. Each of the applications was hosted within this portal as portlets. Figure 2a-2c show screenshots of the urbanAPI applications running in a browser from the web portal taken from the urbanAPI website $^{3}$. In the following section we present an overview of the evaluation methodology implemented by urbanAPI.

\subsection{Evaluation Methodology}

The overall evaluation process as depicted in Figure 3, consisted of the following steps:

1. Evaluation Design: at the evaluation design stage, the Criteria-Indicators-Metrics (CIM) Methodology (Khan, Ludlow \& Caceres 2013) was extended by the authors. The CIM methodology was based on the ISO 9126 Quality Model while CIM2 was based on the more recent ISO 25010 Quality in Use model (Chua \& Dyson 2004; Lew et al. 2010). The methodology is based on defining set criteria and indicators to measure the usefulness of applications by answering specific questions. These included designing the evaluation by defining the criteria based on specific aspects such as usability, functionality, performance, user acceptance, effectiveness, efficiency, compatibility and reliability. In addition to quantitative measures, qualitative assessment is also included, to enable evaluators to provide subjective (and/or objective) assessment mainly concerning the benefits, relevance and the overall impact of the urbanAPI solutions. More specifically, the following activities were performed by the authors:

a. Identification of the main set of criteria based on the requirements specification, application objectives and stakeholder needs.

b. Deriving sub-criteria for each criterion and operationalizing it by identifying one or more indicators to achieve the objectives of the project and its applications.

c. Specifying questionnaire and response options with associated weights to measure the outcomes. Each indicator is represented by one or more questions.

d. Identifying the means to perform specific evaluation exercises to answer the evaluation questions.

2. Design Verification: the evaluation design was verified by engaging with stakeholders in each city who were asked to perform the following activities:

${ }^{3}$ The urbanAPI Project, http:/ / urbanapi.eu [Last accessed: 30 November, 2015] 
a. Verify that the evaluation design contents (i.e. criteria, questionnaire, etc) captured important assessment elements and were in line with their needs and requirements.

b. Highlight the importance (high, medium, low) of specific questions.

c. Indicate improvements in the questionnaire, response options, metrics etc.

d. Identify additional criteria, indicators, questionnaire and metrics, where applicable.

3. Development of Test Cases: test cases were developed by the authors for each pilot city to validate the software in meeting user requirements and needs. The test cases were derived from user requirements and were carried out by developers to show that the software satisfied the test cases as part of the technical evaluation.

4. Evaluation Implementation: in this stage the actual evaluation was carried out by using different mechanisms such as web-based tools, workshops, etc. The evaluation was undertaken by the stakeholders and is described in more detail in Section 5.

5. Evaluation Results and Documentation: all the above stages including evaluation results were documented, compared with related projects (i.e. benchmarking) and verified by the stakeholders.

In the next section we present selected application-specific user requirements, scenarios as well as the evaluation results.

\section{City Pilots}

This section briefly introduces city pilots and the urban context in which the urbanAPI tools were applied.

\subsection{Vienna, Austria}

The need for 3D visualisation tools has been increasingly recognised over the past 10 years in relation to urban development projects in central Vienna. These projects help to avoid the negative impacts of new development on the historic city centre, and so maintain UNESCO recognition of world heritage status of the city. Since that time 3D visualisation of new development proposals has been one of the priorities for urban planning, and as a result Vienna now has a 3D database in CityGrid format (UVM Systems 2013). Current applications using this data are functional and robust, but not appropriate for engagement with members of the public. Furthermore, these applications are static and require more dynamic features such as loading new data and visualisation of new development options for both the general public as well as experts including urban planners and architects.

Even though Vienna's traffic infrastructure has developed significantly over the past 15 years, so today approximately $70 \%$ of daily journeys are by public transport, bicycles or on foot, nonetheless, the demand for more sustainable traffic infrastructure remains. In this regard the Urban Development Plan 
(Stadtentwicklungsplan - STEP), and the Traffic and Transport Master Plan identified sustainable mobility strategies, to minimise travel distances and support the further development of public transport. In this regard Vienna need to secure additional information on mobility behaviour to: i) compare and contrast to existing intelligence and modelling results, ii) gain better insights in mobility and traffic behaviour, iii) gain information about the attractiveness of different areas; and iv) to use as evidence to improve transport and urban planning initiatives in the city.

\subsection{Vitoria-Gasteiz, Spain}

Vitoria-Gasteiz requires tools and technologies that can assist in the management of a number of planning challenges. The city is surrounded by a green belt consisting of rings of various public spaces primarily owned by the city council. Proposals for the implementation of an inner green belt are now under development, to form the foundations for an urban green infrastructure system (City Council of VitoriaGasteiz 2012) interspersed with various public spaces. The city is seeking to involve citizens in the development of these proposals, and a 3D visualisation tool that assists citizens to explore the proposed plans in 3D is seen as beneficial. Furthermore, the development of the inner green belt also necessitates the production of better mobility management plans in order to reduce traffic volumes and promote sustainable mobility, as well as actions to improve public spaces and increase their attractiveness and accessibility.

\subsection{Bologna, Italy}

Bologna aims to communicate more effectively with citizens by visualising future development and potential impacts, and to enhance public engagement supporting more effective feedback on planning initiatives. In Bologna, the San Vitale District is located in the eastern part of the city and covers both central and peripheral areas. The central part of the district will form part of a rehabilitation and mobility plan where the municipality is developing proposals to create new public spaces in order to connect the district with the urban core, enhancing local sustainability. Implementation of the initiative requires public participation to raise awareness of the benefits of the scheme. Citizens as well as citizen committees and cultural associations in this area are already substantially involved in public interventions suggesting a prime location to implement and test participatory ICT applications.

\subsection{Ruse, Bulgaria}

The Ruse municipality and city region possesses great potential for socio-economic and industrial development, but also faces major challenges in the effective management of urban development. The city municipality is seeking suitable mechanisms to model future urban development of the city region, and visualise its effects, in order to develop better city-region planning guidelines specified in the Master Plan of the city. The plan defines a set of aims with functional, spatial and environmental characteristics, as well as specific objectives for each of the main functional systems, including residence, employment, recreation, transport 
infrastructures. Furthermore, a key requirement for modelling the future urban development of the city is to include citizen preferences in the predicted developments.

Having discussed the socio-economic and political contexts within which urbanAPI tool were developed, the next section considers the results of the evaluation exercises conducted in these cities.

\section{Application-Specific Evaluation Results}

The evaluation was carried out in two cycles, with cycle 1 marking the completion of the first round of application development. Evaluation workshops were organised in the pilot cities and users were asked to test the applications. Feedback was collected through online questionnaires prepared according to the methodology discussed in Section 3.5. The results were then analysed and documented. The feedback from the first evaluation cycle was then incorporated into the user requirements for the second development cycle. Upon completion of the second cycle, the cycle 2 evaluation was carried out. As with cycle 1, evaluation workshops were organised in the pilot cities, but this time, following feedback from the cycle 1 evaluation on the need for user training, the cycle 2 evaluation workshops were preceded by user training workshops. In the workshops approximately 15 users participated in the evaluation exercises representing different stakeholder interests ${ }^{4}$ e.g. urban planners, GIS experts, transport planners. etc.

In order to fully understand the evaluation results, the following elaborates brief summaries of application specific scenarios and requirements, that are fully documented in the project deliverables.

\subsection{D Scenario Creator (3DSC)}

\subsubsection{User Requirements}

Table 2 shows selected Vienna requirements for the 3DSC. In addition to these requirements, a number of usage scenarios were also identified in consultation with the users. For example, the following is an excerpt from usage scenarios identified for Vienna.

\section{Scenario A: Assessing Development Proposals in Architectural Competitions}

Mr. Seidler works for the Urban Planning department of the city of Vienna. A new urban development area is proposed and as usual an architects' competition has been arranged. As a result, Mr. Seidler receives a number of drafts (as digital 3D-data) from the architects. He wants to be able to use an information system that can take architectural design data as an input and visualise a $3 D$ architectural model in relation to city map and other socio-economic elements. Furthermore, he wants to visualise impacts for the city if certain architectural

"The results presented in this paper are discussed in more detail in the project deliverable "D5.4 - User Evaluation (II)", which can be provided upon request. 
variables are modified. This will help Mr. Seidler in comparing various architectural design options for the development area and measuring impacts on the city.

\section{Scenario B: Shadow Analysis for New Urban Development}

Ms. Sofia works for Vienna Urban Planning department, and is responsible for the analysis the impacts of the shadows of new urban development on neighbouring buildings in the City. Her aim is to detect the movement of the shadows of buildings over time on the neighbouring buildings, and so assess the implications of Vienna's two hour shadow policy.

\subsubsection{Evaluation Questionnaire}

Based on the requirements and the scenarios identified, evaluation questionnaires for each city were designed. Table 3 shows an excerpt from the Vienna 3DSC questionnaire.

\subsubsection{Results}

Since the 3DSC application consists of three distinct components, the evaluation for each component was carried out separately. Approximately 5 participants took part in the evaluation of 3DSC application finding that the application:

- supports planning and visualisation of future development scenarios as well as communicating them to the public and acquiring their feedback;

- helps citizens understand the benefits and implications of the development proposals;

- allows wider citizen participation in the decision-making processes of the city.

In general GIS experts found the application more useful than urban planners. This may be because GIS experts are more familiar with loading, manipulating and visualising geo-spatial data using ICT tools, assisting them in understanding and using the 3DSC tool. The overall evaluation score for Vienna is shown in Figure 4. As can be seen the application scored above $50 \%$ in all scenarios while scoring the highest in the general questions category, where questions focused mainly on the benefits and usability of the application.

Some of the drawbacks identified by users included the lack of integration between the various components of the application which hampered usability. For example, some users could not clearly understand the purposes of the web interface, the Admin Tool and the Rule Editor. This was mainly due to lack of comprehensive training in use of the 3DSC application. For this reason users missed some functionality that was available in another component. Moreover, in cases where the 3D model was based on data extrapolated from 2D, users found it difficult to relate the various virtual locations to real-world locations. This was due to the lack of texture in the $3 \mathrm{D}$ visualisations. However, this is not a limitation of the application itself; rather of the data available. In addition, the fact that not all components of the 3DSC application are web-based was also a cause for concern as it limited collaboration. 


\subsection{Mobility Explorer (ME)}

\subsubsection{User Requirements}

Selected requirements for the ME application are shown in Table 4. As with the 3DSC application various user scenarios were defined as follows.

Scenario A: Evaluation of the Implementation of the Sustainable Mobility and Public Space Plan

Vitoria-Gasteiz Public Space Department has undertaken first steps in the Implementation of the Sustainable Mobility and Public Space Plan, with the development of the first superblock: Sancho el Sabio. Other actions have also commenced in the implementation of the main central superblock. As pilot areas, planners need to understnad how these urban transformations influence mobility and the use of the public space in the city.

Scenario B: Site Suitability Analysis for a Commemorative Monument

Vitoria-Gasteiz Public Space Department is considering the location for a commemorative monument to the European Green Capital. There are different views on the best location which needs to maximise enjoyment by both citizen and visitor.

Scenario C: Selection of Improvement Actions in Pedestrian Areas

One proposal of the Sustainable Mobility and Public Space Plan concerns street improvements to foster pedestrian mobility. The plan has a small budget and a large number outstanding street improvement actions. All cannot be funded.

\subsubsection{Evaluation Questionnaire}

As with the 3DSC evaluation, questionnaires for each city were designed based on user requirements and scenarios. An excerpt from one such questionnaire is shown in Table 5.

\subsubsection{Results}

The ME application aims to engage domain experts including urban and transport planners rather than citizens. The ME relies entirely on the available data to support its functionality, and for this reason, the application functionality is highly sensitive to the granularity of the data. Consequently the application could only be fully demonstrated for Vienna, as the city has a relatively dense concentration of cell towers, as compared to Vitoria-Gasteiz. Furthermore, in Bologna the acquisition of fine grained mobile phone use data was challenging. Since the ME application extrapolates the mobility patterns from the times that mobiles connect and disconnect with specific cell towers, it was not possible to perform these extrapolations in the case of Vitoria-Gasteiz and Bologna .

Despite the above limitations, users did appreciate the usefulness, usability and simplicity of the application. Moreover, since it is web-based, collaboration between different user communities is facilitated supporting better communication and coordination amongst different stakeholders. 
The overall evaluation scores achieved by the application for Vitoria-Gasteiz are shown in Figure 5. The low scores in the case of Scenarios A, B and C have already been explained, due to the lack of sufficiently granular GSM data. However, the application scored $56 \%$ in the case of general questions, which focused on its usability and benefits, and shows despite some limitations, users found the application beneficial.

\subsection{Urban Development Simulator (UDS)}

\subsubsection{User Requirements}

Selected user requirements for the UDS application are shown in Table 6. Four scenarios were identified for the UDS application, including the following example.

\section{Scenario A: Ex-post and Ex-ante Trend-Simulation for the Ruse urban region}

Ruse urban region planning agency need to identify and simulate location decisions of households and business, driven by regional attractiveness patterns, under current and future conditions, and to visually communicate the impact of various planning alternatives to stakeholders. Accordingly, when simulating the spatial development of the entire urban region, the overall trends can be understood and the municipalities can be identified as more or less attractive areas for development.

\subsubsection{Evaluation Questionnaire}

For the UDS application the evaluation questions, based on the requirements and scenarios identified shown in Table 7 were identified amongst others.

\subsubsection{Results}

The evaluation results, based on the participation of four users from the city of Ruse, confirm that users rated the various functionalities provided by this application favourably. These include identification of the effects of urban growth and shrinkage, acquiring relevant information about possible future changes in population distribution and building development, and enabling public participation in urban planning initiatives. However, it should be noted that it is difficult to validate the results of the ex-ante simulations especially where detailed or high quality city data is not available, as UDS forecasts socio-economic activity over a period of decades, and subsequent planning interventions and changing citizen preferences over time influence the outcomes. Furthermore, the number of evaluators was comparatively small, and so the results of the evaluation cannot be generalised and are not statistically significant. However, they do give a good idea of the usefulness and applicability of the tool.

\section{Critical Reflection and Discussion}

The evaluation results help in assessing the effectiveness of three urbanAPI participatory applications at different urban scales in the four pilot cities. In this 
section we critically reflect on the results and the overall process of evaluating these applications.

\subsection{City Governance Requirements}

The effective governance of the cities and city regions of Europe today must address urban complexity, whereby the high degree of interconnectedness and multiple interactions between socio-economic and environmental factors in a territorial context create major barriers to the effective specification and implementation of sustainable urban development. This interconnectedness and complexity of the urban environment can only be effectively managed via integrated urban management processes which aim to address the gaps between sectoral policies, between planning and implementation processes, and between different departments and stakeholders, across functional urban regions, where competition between municipalities often exceeds collaboration.

In particular the land use planning policy model specifies territorial decision-making procedures as the basis for inter-agency collaboration, and forms the fundamental integrating force of urban territorial governance. However, this governance model is under challenge in response to the substantial demands by urban complexity for an integrated assessment, and inter-agency collaboration. In response innovation driven bottom-up participatory governance aims to enhance the functioning of the policy model supporting integrated urban management and facilitating inter-agency collaborations to deliver more effective territorial decision-making (Moulaert et al. 2007). The dynamic of ICT innovation in tandem with social innovation, is accordingly driving the transformation of the policy model, providing a stimulus to social innovation where citizens can engage in participatory planning processes, provide new insights in policy making and co-produce plans (Linders 2012).

The extent to which the urbanAPI tools effectively extend the state-of-the-art in meeting the challenges of integrated management of urban complexity are considered in the following section with reflection on the contributions of each tool. The subsequent section (section 5.3) identifies some specific tool limitations before more general conclusions are drawn in the context of the potentials of the tools to support co-design and co-production of urban plans.

\section{2 urbanAPI tools - Assessment and Impact}

This section critically reflects on the urbanAPI evaluation results from perspectives which are central to the user requirement and the project objectives, including the dynamic of the policy development process. The urbanAPI tools are designed to support various stages of the policy-making process, driving integrated urban management, as well as participatory and evidence based urban planning that is essential to effective decision making. The generic policy model (Figure 6) depicts a cycle representing different stages of the policy-making process, as follows:

Issue Identification: from a top-down policy making perspective additional and novel stakeholder issues may be identified by deploying the ME or UDS 
applications, as well as the 3DSC tool to engage stakeholders and support public participation in the planning process.

Agenda Setting: concerns the formulation of a coherent planning strategy, specified by urban planners in respect of a variety of policy objectives. All three urbanAPI applications support this stage by facilitating the development of alternative scenarios including proposals and suggestions by stakeholders.

Development and Analysis: provides an assessment of the territorial impacts of plan solutions, in respect of socio-economic and environmental variables. Here participatory 3D sketching (3DSC) supported by ME-driven impact assessment and UDS simulation offers significant added value in the development and analysis of various development proposals.

Negotiation/Decision-Making: All three urbanAPI applications support proposals for the future development of the urban territory facilitating public and wider stakeholder consultation fundamental to the political acceptance of the plan, by elected officials of the municipality prior to the implementation of the plan.

Implementation: based on commitments by a variety of public agencies over the plan period, typically lasting several years, to secure the objectives of the plan. While urbanAPI applications may not directly be involved in this stage of the policy cycle, nonetheless stakeholder engagement facilitates the development of political drive supporting the implementation of the plan.

Evaluation: focused on monitoring the implementation of the plan to identify the extent to which it is achieving its policy objectives, forming the basis for strategic revision of the plan, as part of cyclical process of plan implementation. Again all three urbanAPI applications support this stage of the plan process by permitting planners to visualise and measure the dynamic of the city, and engage with stakeholders in assessment of the outcomes.

\section{Evaluation Overview}

Based on the urbanAPI evaluation process it is concluded that the urbanAPI tools substantially assist in transforming policy making and decision making processes by generating targeted intelligence supporting decision making, by enhancing communication between all governance agencies and actors, and by engaging with various stakeholders including the public at most of the stages of the policy development cycle.

Critically, urbanAPI tools provide the key to unlock the essential "upstream" engagement of stakeholders at the agenda setting stage of the decision making process, compared with traditional participatory governance focus on the "downstream" negotiation/decision making stages, when it is no longer possible to influence the framework conditions for specification of the plan.

Assessed with reference to the classic conceptualisations of participatory governance provided by Arnstein (Arnstein 1969), the urbanAPI tools are strongly related to, 
and operative in the framework of "consulting" and "informing". This is Arnstein's middle ground, and clearly less ambitious than her higher order engagement involving "partnership" and beyond "delegated power". Nonetheless, the tools can provide a useful stepping stone towards open governance models in which consultation is an essential precondition for partnership and co-design. The limitations are not so much in the design of the tool, but rather the political will to pursue open governance, and wider and deeper stakeholder engagement.

Specifically, the 3DSC application promotes active participatory planning where end users can participate via web browser (using X3DOM technology) to identify urban issues for a specific planning proposal e.g. by providing annotations, placing visual objects at specific locations such as street furniture, new infrastructures/buildings etc. This application helps city administrations in raising awareness by communicating planning issues to the public with the objective to empower them in the identification and debate on local issues.

From a different perspective the ME application actively supports the identification of the evidence base for urban planning in defining the spatio-temporal patterns of socio-economic activity in the city and relating these to the spatial structure of the urban area. This provides unique and highly significant insights into collective behaviours in the urban environment essential to the pursuit of evidence-based urban and transport planning. Population distribution and mobility patterns are identified by using mobile phone data and presented through a web-based visual interface. The visualisation results can be exported to other statistical and spatial tools for further analysis and impact assessment. In urbanAPI, the ME is considered a highly relevant and beneficial source of information which otherwise is not available at reasonable cost for cities.

The UDS application supports participation based on the ex-post model calibration, using historic city data and/or citizen participation to develop behaviour rules and use these rules for ex-ante trend simulations. This participation is supported by on online evaluations conducted for planning interventions, with results used to calibrate simulation models.

These various and substantial benefits of urbanAPI tools identified above provide a clear basis for responses to the research question posed in Section 1. All indications suggest that the urbanAPI applications are effective enablers of smart city governance in enhancing the production of urban plans and redefining the opportunities for enhanced bottom-up engagement in decision making processes. However, certain limitation and challenges were also identified with urbanAPI applications as discussed in the next section.

\subsection{Limitations and Challenges}

The evaluation of urbanAPI tools identified the following limitations and challenges with regards to meeting user needs and requirements: 
1) The 3DSC meets many of the cities' requirements. However, it is highly dependent on the quality of the 3D data available. This was a problem for smaller cities like Vitoria-Gasteiz and Bologna as there was no high quality 3D data. Therefore, many functionalities of the application could not be used in their case. For example, users found it difficult to relate the 3D model to actual landmarks since the various buildings in the 3D model did not look like their real-life counterparts. In Vienna this was not a problem as they have sophisticated 3D models available.

2) Since some of the components of the 3DSC are not web-based, this was also a problem. This made it difficult to share and collaborate on urban development proposals. Another problem arising from this is that some municipalities do not allow users to install unauthorised software on their computers. Therefore many users could not get access to the software easily.

3) One of the future directions identified from the urbanAPI project is to enable users to automatically predict the consequences of development proposals. For example, number of jobs created, increase/decrease in $\mathrm{CO}_{2}$ emissions, increase/decrease in traffic congestion etc. However, implementing this feature will require well-defined models and additional data.

4) The ME was appreciated for its simplicity and straightforwardness. However, users did suggest that the application could provide more useful guidance on it's use.

5) Users also requested that the ME be provided in the local language, to increase its usability.

6) One of the problems faced by the developers with regards to the ME was that the application functionality is highly sensitive to the distribution and density of mobile cell towers in the city. The application operates by tracking cell phones as they connect and disconnect to various cell towers. In smaller cities like VitoriaGasteiz and Bologna, the density of cell towers was not sufficient to be able to accurately track the movement of citizens within the city. Therefore, the ME was found to be more useful for larger cities like Vienna with high population, and consequently, cell tower densities.

7) Another limitation of the ME that was identified was that there was no overlay of mobility data with other sources of data such as facility locations, housing densities etc. These kinds of overlays are useful when analysing the attractiveness of public spaces.

8) Most of the feedback regarding the UDS was positive. The only drawback that was identified was that it was difficult to validate the predictions made by the application. Also, fine grained data is needed for ex-ante and ex-post simulation which in many cities may not be available.

9) The urbanAPI project did not involve citizens at any stage of the project, as two of the three tools developed are intended for expert users only. The ME and the UDS tools support participatory governance by incorporating citizen-generated data. In the case of ME, it is mobile GSM data and in the case of the UDS it is citizen preferences collected through various questionnaires. Only the 3DSC, 
used directly by citizens to engage with development proposal, could benefit from involving citizens in the requirements definition and evaluation stages. Accordingly the 3DSC is more expert-oriented, although this limitation is being addressed in the follow-on Smarticipate project ${ }^{5}$ where citizens are more actively engaged.

Finally, returning to the potential limitations of the research methodology identified in the introduction to this paper, concerning the framework of plan co-production and multi-stakeholder engagement. Given the essential top-down perspective of the research, questions may arise regarding the appropriateness and effectiveness of the results, and whether greater advance to this particular state-of-the-art would have been achieved using a multi-stakeholder co-production development model. Based on the above assessment of the tools it is considered that all 3 tools developed offer significant potentials in an environment of plan co-production where issues concerning inter-stakeholder communication, common understanding and development of consensus are central. The tools for collaborative participation, visualisation of urban development, and simulation of urban futures that urbanAPI provides all support these objectives.

\section{Conclusions}

This paper describes and analyses user perspectives on the effectiveness of urbanAPI tools and methodologies in promotiong the development of an integrated, more powerful and effective urban governance. The purpose of the tools is to manage the most intractable urban planning issues, including the management of the complexity of urban interactions, specified in socio-economic activity, set within both environmental limits and the territorial frame.

The user perspective recognises that this transformational governance requires greater stakeholder engagement in the urban planning process. Municipal experts providing a top-down view of the urban vision, and its local level specification, are no longer able to manage the inherent complexity of the sustainable city alone. Greater bottom-up stakeholder engagement thereby secures the quality of integrated assessment necessary to effectively plan the modern city, providing inputs in respect of the political diversity of views on the best way forward, all essential to secure the democratic legitimacy of the urban plan.

The paper also provides a detailed overview of the urbanAPI governance applications; the 3D Scenario Creator (3DSC), the Mobility Explorer (ME) and the Urban Development Simulator (UDS). Each of these applications, implemented in four pilot cities, relates to specific aspects of participatory governance. The 3DSC application enables planners to generate 3D visualisations of proposed urban development plans and communicate them to various stakeholders through a web interface. The Mobility Explorer (ME) application allows planners to harvest citizens'

${ }^{5}$ http: / / smarticipate.eu 
location data over time and to visualise mobility patterns in relation to the spatial and land use characteristics of the built environment. The Urban Development Simulator (UDS) allows planners to simulate future evolution of the urban environment according to three key variables including socio-economic dynamics, planning and environmental constraints, and stakeholder preferences.

In total urbanAPI tools and methodologies are simultaneously sources of intelligence, and means of communication, and so in principle perform vital roles in supporting bottom-up engagement in the planning process as an essential complement to the top-down municipal system of guidance. The actual performance of the tools, based on the results of the evaluation of the three applications show that while there are some issues related to usability of the applications, they are nonetheless highly effective in visualising the impacts of proposed urban plans and development scenarios, and in communicating the impacts of these plans to various stakeholders to secure their feedback. Overall, the evaluation results show that the urbanAPI applications do assist in supporting decision-making at various stages of the policy-making cycle. They are useful in enabling collaborative and participatory planning, as well as top-down issue identification, confirming their great potential for supporting sustainable urban development strategies both at city-wide and neighbourhood levels.

The conceptual frame for the project is based upon the understanding that urban managers throughout Europe face common challenges in responding to the need to secure urban economic vitality, social inclusion and environmental sustainability. The commonality of the drivers of urban change offers a major opportunity for the development of common solutions. These solutions are based on the development of generic ICT applications and methodologies, grounded in effective citizen and wider stakeholder engagement in the planning process. urbanAPI directly addresses these potentials for the development of common models of policy formulation and implementation in respect of information generation and management, as well as stakeholder engagement, thereby supporting the potential for widespread application of the tools developed throughout the cities and regions of Europe.

Furthermore, beyond urbanAPI these tools also have the potential to drive new experiments in the co-design and co-production of plans, in which technological opportunity including social media allied to other ICT dynamics, such as mobile technologies supporting citizen science, has significantly enlivened the dynamic of governance supporting more effective integrated and participatory urban governance.

Evaluating a collaborative IT based research and development project

\section{References}

Agarwal, N., 2015. Liferay Portal 6.2 Enterprise Intranets, Birmingham, UK: Packt Publishing.

Al-Kodmany, K., 2002. Visualization Tools and Methods in Community Planning: 
From Freehand Sketches to Virtual Reality. Journal of Planning Literature , 17(2), pp.189-211.

Albrechts, L. \& others, 2010. More of the same is not enough! How could strategic spatial planning be instrumental in dealing with the challenges ahead? Environment and planning. B, Planning $\mathcal{E}$ design, 37(6), p.1115.

Arnstein, S.R., 1969. A Ladder Of Citizen Participation. Journal of the American Institute of Planners, 35(4), pp.216-224.

Boyd, S. \& Chan, R., 2002a. Placemaking tools for community action. Concern, Inc. Environmental Simulation Center, US Department of Energy, Denver.

Boyd, S. \& Chan, R., 2002b. Placemaking tools for community action. Concern, Inc. Environmental Simulation Center, US Department of Energy, Denver.

Chua, B.B. \& Dyson, L.E., 2004. Applying the ISO 9126 model to the evaluation of an e-learning system. In Proc. of ASCILITE. pp. 5-8.

City Council of Vitoria-Gasteiz, 2012. The Interior Green Belt. Towards an Urban Green Infrastructure in Vitoria-Gasteiz. Available at: http://www.vitoriagasteiz.org/wb021/http/contenidosEstaticos/adjuntos/es / 44411.pdf [Accessed 17 September, 2016].

Doyle, S., Dodge, M. \& Smith, A., 1998. The potential of Web-based mapping and virtual reality technologies for modelling urban environments. Computers, Environment and Urban Systems, 22(2), pp.137-155.

ESPAS, 2013. The Global Economy in 2030: Trends and Strategies for Europe. Available at: http://europa.eu/espas/pdf/espas-report-economy.pdf [Accessed 6 November, 2015].

Fung, A., 2015. Putting the Public Back into Governance: The Challenges of Citizen Participation and Its Future. Public Administration Review, 75(4), pp.513-522.

Hanzl, M., 2007. Information technology as a tool for public participation in urban planning: a review of experiments and potentials. Design Studies, 28(3), pp.289307.

Jacquier, C., 2005. On relationships between integrated policies for sustainable urban development and urban governance. Tijdschrift voor economische en sociale geografie, 96(4), pp.363-376.

Janssen, M. \& Zuiderwijk, A., 2012. Open data and transformational government. In TGov Conference, London.

Kahila, M. \& Kyttä, M., 2009. SoftGIS as a bridge-builder in collaborative urban planning. In Planning support systems best practice and new methods. Springer, pp. 389-411.

Khan, Z., Ludlow, D., et al., 2014. ICT enabled participatory urban planning and policy development. Transforming Government: People, Process and Policy, 8(2), pp.205-229.

Khan, Z. et al., 2015. Towards cloud based big data analytics for smart future cities. Journal of Cloud Computing, 4(1), p.2.

Khan, Z., Kiani, S. \& Soomro, K., 2014. A Framework for Cloud-based ContextAware Information Services for Citizens in Smart Cities. Journal of Cloud Computing: Advances, Systems and Applications, 3(1), p.14.

Khan, Z., Ludlow, D. \& Caceres, S., 2013. Evaluating a collaborative IT based research and development project. Evaluation and program planning, 40, pp.27-41.

Khan, Z., Ludlow, D. \& Loibl, W., 2013. Applying The CoRes Requirements 
Development Method For Building It Tools For Urban Management Systems: The Urbanapi Project. Theoretical and Empirical Researches in Urban Management, $8(4)$, pp.25-59.

Kyttä, M., 2011. The inhabitant friendly, health promoting urban structure. GUEST EDITOR, p.72.

Lang, V. \& Sittler, P., 2012. Augmented reality For real estate. In Research Paper, 18th Pacific-RIM Real Estate Society (PRRES) Conference, Adelaide, Australia.

Lew, P., Olsina, L. \& Zhang, L., 2010. Web Engineering: 10th International Conference, ICWE 2010, Vienna Austria, July 5-9, 2010. Proceedings. In B. Benatallah et al., eds. Berlin, Heidelberg: Springer Berlin Heidelberg, pp. 218232.

Liberatore, A. \& Funtowicz, S., 2003. "Democratising" expertise, "expertising" democracy: What does this mean, and why bother? Science and Public Policy, 30(3), pp.146-150.

Linders, D., 2012. From e-government to we-government: Defining a typology for citizen coproduction in the age of social media. Government Information Quarterly, 29(4), pp.446-454.

Loibl, W. \& Peters-Anders, J., 2012. Mobile phone data as source to discover spatial activity and motion patterns. G1_Forum, pp.524-533.

Manoharan, T., Taylor, H. \& Gardiner, P., 2002. A Collaborative Analysis Tool for Visualisation and Interaction with Spatial Data. In Proceedings of the Seventh International Conference on 3D Web Technology. Web3D '02. New York, NY, USA: ACM, pp. 75-83.

Moulaert, F. et al., 2007. Introduction: Social Innovation and Governance in European Cities: Urban Development Between Path Dependency and Radical Innovation. European Urban and Regional Studies, 14(3), pp.195-209.

Parycek, P. \& Sachs, M., 2010. Open government--information flow in Web 2.0. European Journal of ePractice, 9(1), pp.1-70.

Peters-Anders, J. et al., 2014. Exploring Population Distribution and Motion Dynamics through Mobile Phone Device Data in Selected Cities--Lessons Learned from the UrbanAPI Project. In 19th International Conference on Urban Planning, Regional Development and Information Society - REAL CORP 2014. Vienna: REAL CORP 2014 Tagungsband, pp. 871-876.

Sarkan, H.M., Ahmad, T.P.S. \& Bakar, A.A., 2011. Using JIRA and Redmine in requirement development for agile methodology. In 2011 Malaysian Conference in Software Engineering. IEEE, pp. 408-413.

Stellingwerff, M. \& Kuhk, A., 2004. 3D/4D communication tools for facilitators in public participation. In Architecture in the Network Society. Proceedings of the 22nd Conference on Education and Research in Computer Aided Architectural Design. Copenhagen, pp. 15-18.

The Open Government Working Group, 2012. Open Government Data. Available at: http: / / opengovernmentdata.org/ [Accessed 30 November, 2015].

UVM Systems, 2013. CityGrid. Available at: http:/ / www.uvmsystems.com/index.php/en/ [Accessed 1 April, 2016].

Wampler, B. \& McNulty, S.L., Does Participatory Governance Matter? Available at: Www.wilsoncenter.org/publication/does-participatory-governance-matter [Accessed 30 November, 2015].

Weber, E.P. \& Khademian, A.M., 2008. Wicked Problems, Knowledge Challenges, 
and Collaborative Capacity Builders in Network Settings. Public Administration Review, 68(2), pp.334-349.

Weerakkody, V. \& Dhillon, G., 2008. Moving from e-government to t-government: A study of process reengineering challenges in a UK local authority context. International Journal of Electronic Government Research, 4(4), pp.1-16.

Weerakkody, V., Janssen, M. \& Dwivedi, Y.K., 2011. Transformational change and business process reengineering (BPR): Lessons from the British and Dutch public sector. Government Information Quarterly, 28(3), pp.320-328.

Tables

Table 1: City Participation Matrix

\begin{tabular}{lcccc}
\hline $\begin{array}{c}\text { City / } \\
\text { Application }\end{array}$ & Vienna & Vitoria-Gasteiz & Bologna & Ruse \\
\hline 3DSC & $\checkmark$ & $\checkmark$ & $\checkmark$ & \\
ME & $\checkmark$ & $\checkmark$ & $\checkmark$ & \\
UDS & & & & $\checkmark$ \\
\hline
\end{tabular}

Table 2: Selected 3D Scenario Creator Requirements

Software should be able to compute shadow situation at city sites as per city policy.

Software should be able to visualise and evaluate the impact of an urban development project on the city.

Software should be able to provide automated workflow (for example wizards) for different scenarios (for example supporting data loading and performing shadows and visibility analysis of new constructions).

End users must be able to export visualisation screen images as well as $3 \mathrm{D}$ visualisation model as a whole.

Software should be able to load architecture data from 3rd parties.

Table 3: Excerpt from 3DSC Questionnaire for Vienna

1. The 3DSC effectively helps expert users to plan, create and visualise future neighbourhood models in 3D.

2. The 3DSC helps to communicate a proposed neighbourhood plan in $3 \mathrm{D}$ to different stakeholders i.e. expert users and citizens.

3. The 3DSC aids expert users and citizens in understanding the impact of the proposed rehabilitation of the neighbourhood.

4. The 3DSC web interface facilitates wider public participation in the planning process. 
Table 4: Selected Requirements for the ME Applications

System must be able to show population density for selected spatial aggregates during weekdays and weekends.

System should be able to segregate mobile patterns when mobile phones are in buildings and outside buildings.

System should consider other sources of data e.g. smart phone GPS data, polls and surveys etc for calibration with GSM data.

System should be able to accurately capture and show real end-to-end distance coverage by selected individuals for origin-destination matrices.

System must provide intra-city and extra-city origin destination matrix acquired from diurnal daytime mobility patterns.

Table 5: Except from ME Evaluation Questionnaire

Does ME provide useful information for evaluating planning decisions?

Does ME provide an efficient method to visualise city population distribution and mobility patterns?

Does ME enable effective passive public participation using mobile data in city transport planning?

Does ME provide useful input for evidence-based decision-making and policy development?

Does ME demonstrate its usefulness to different stakeholders including urban planners, transport planners and policy makers?

Does ME application output complement other sources of data regarding population distribution and mobility patterns?

Does ME enable planners to better understand variations in diurnal population distribution and mobility patterns in the city?

Table 6: Selected UDS User Requirements

System should be able to define appropriate behavioural rules for agent based simulation based on specific attractiveness criteria.

System should present to users the temporal modifications of the different observed assets or components both in $3 \mathrm{D}$ animation or in a set of historically referred maps System should consider other sources of data e.g., polls and surveys etc for calibration of modelled data.

Software must be able to visualise the general attractiveness of a selected region/area.

End users must be able to export visualisation screen images as well as simulation results as a whole. 
Table 7: Selected UDS Evaluation Questions

Do you think that UDS is a useful investigation tool to identify effects of urban growth/shrinkage and help in comparing its output with Master Plan of Ruse?

Do you think that UDS provide useful insights for future urban planning initiatives that can result in sustainable urban development?

Does trend simulation by UDS generate useful information for different expert users e.g. urban planners, policy makers?

Are UDS results effective in acquiring necessary information about possible future changes in population distribution, effects of households and workplaces on new buildings construction/demolition, industrial and commercial areas and additional traffic load?

Do you think UDS provide useful mechanism (e.g. online survey) to support Ruse public participation in urban planning initiatives?

Does UDS provide sufficient evidence based on past data on urban changes that can support decision making and policy making?

\section{Figures}

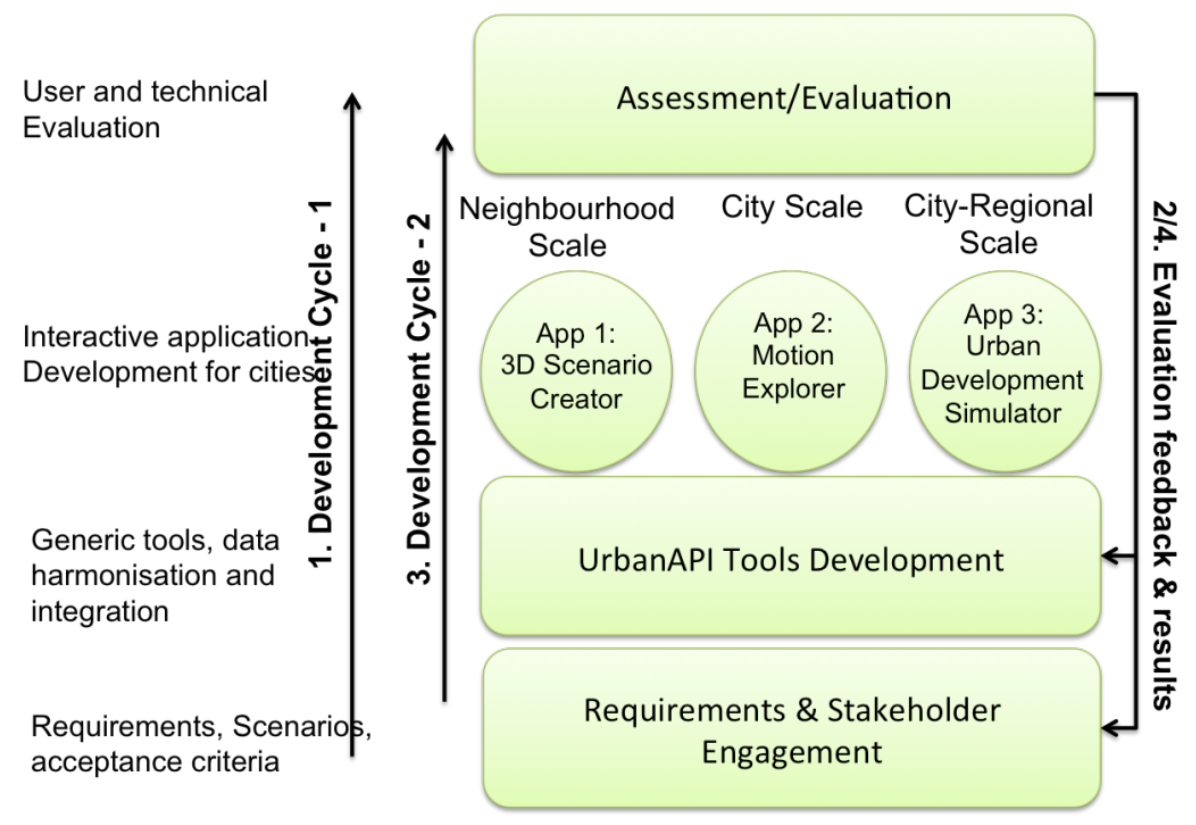

Figure 1: urbanAPI Development Methodology 


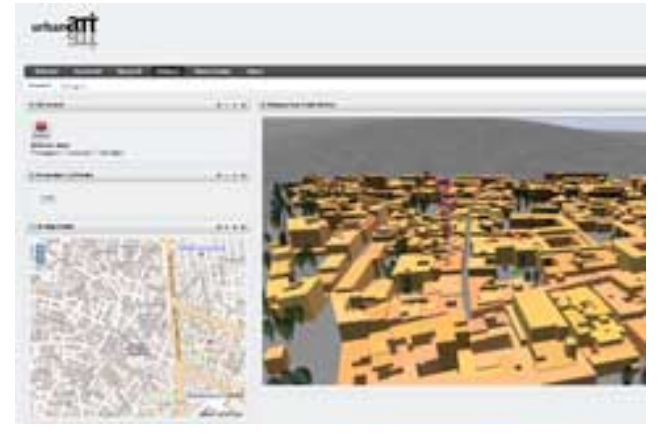

Figure 2a: : 3DSC Application

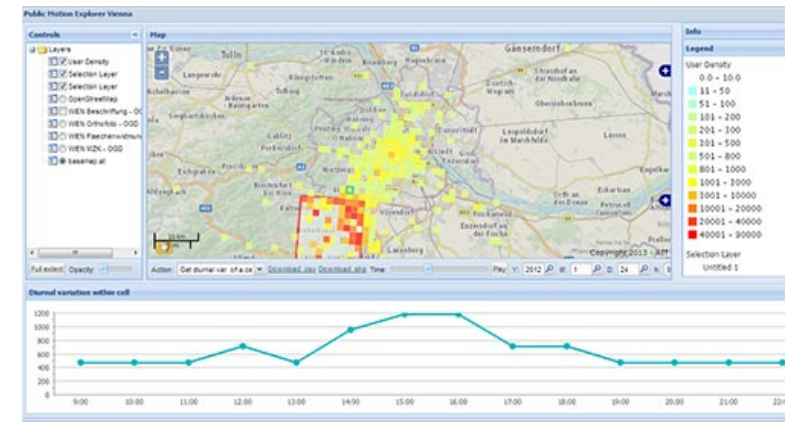

Figure 2b: ME Application

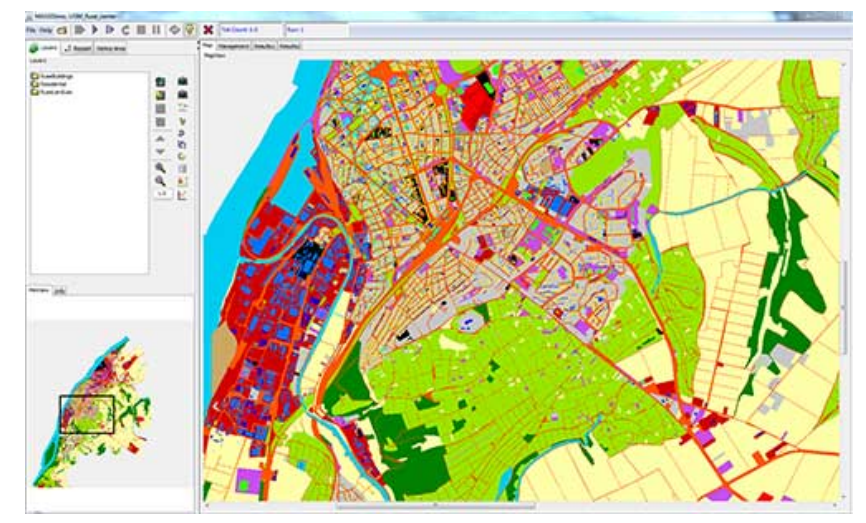

Figure 2c: UDS Application

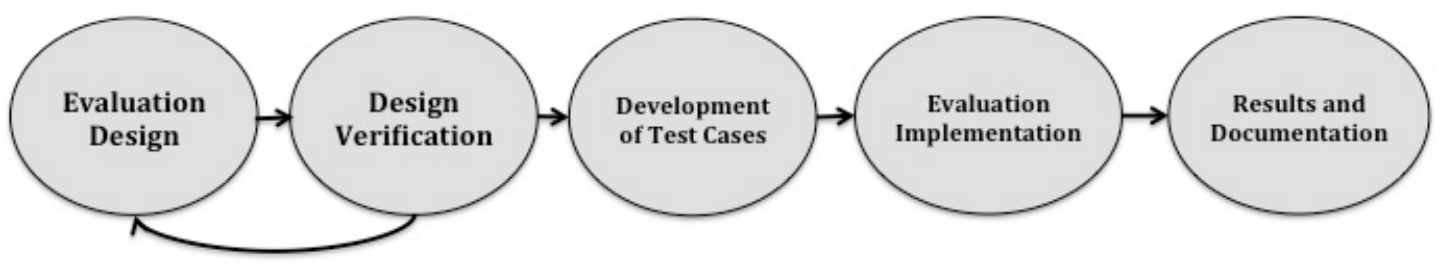

Figure 3: Evaluation process

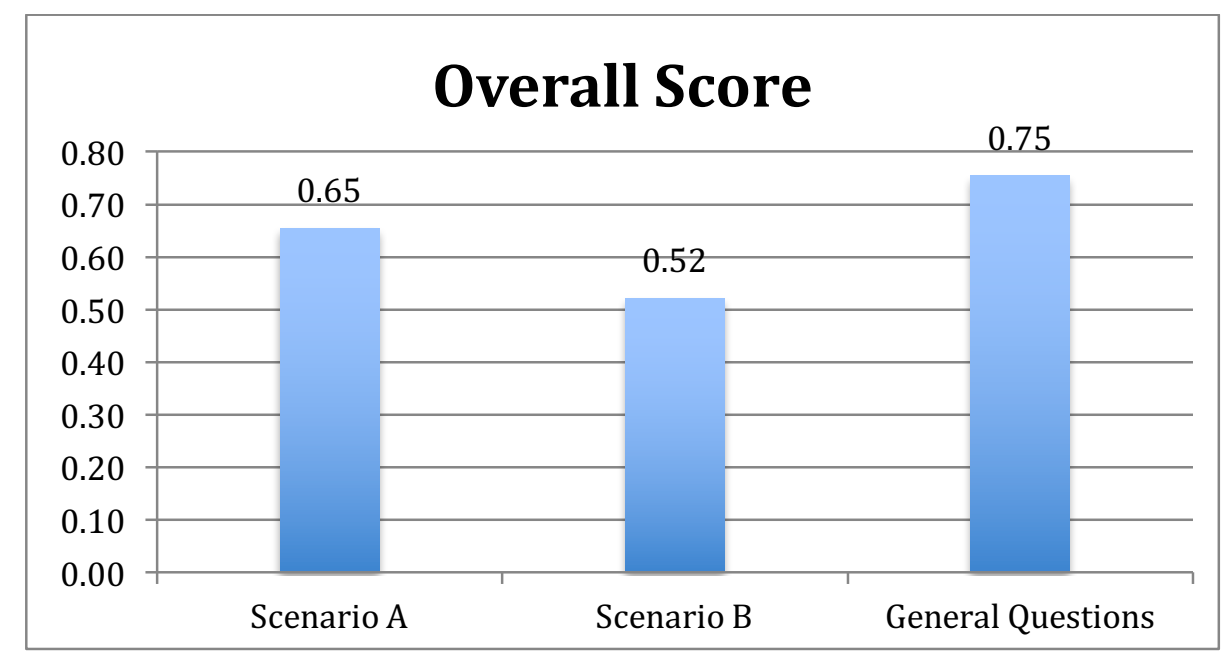

Figure 4: Overall Evaluation Score for Vienna 


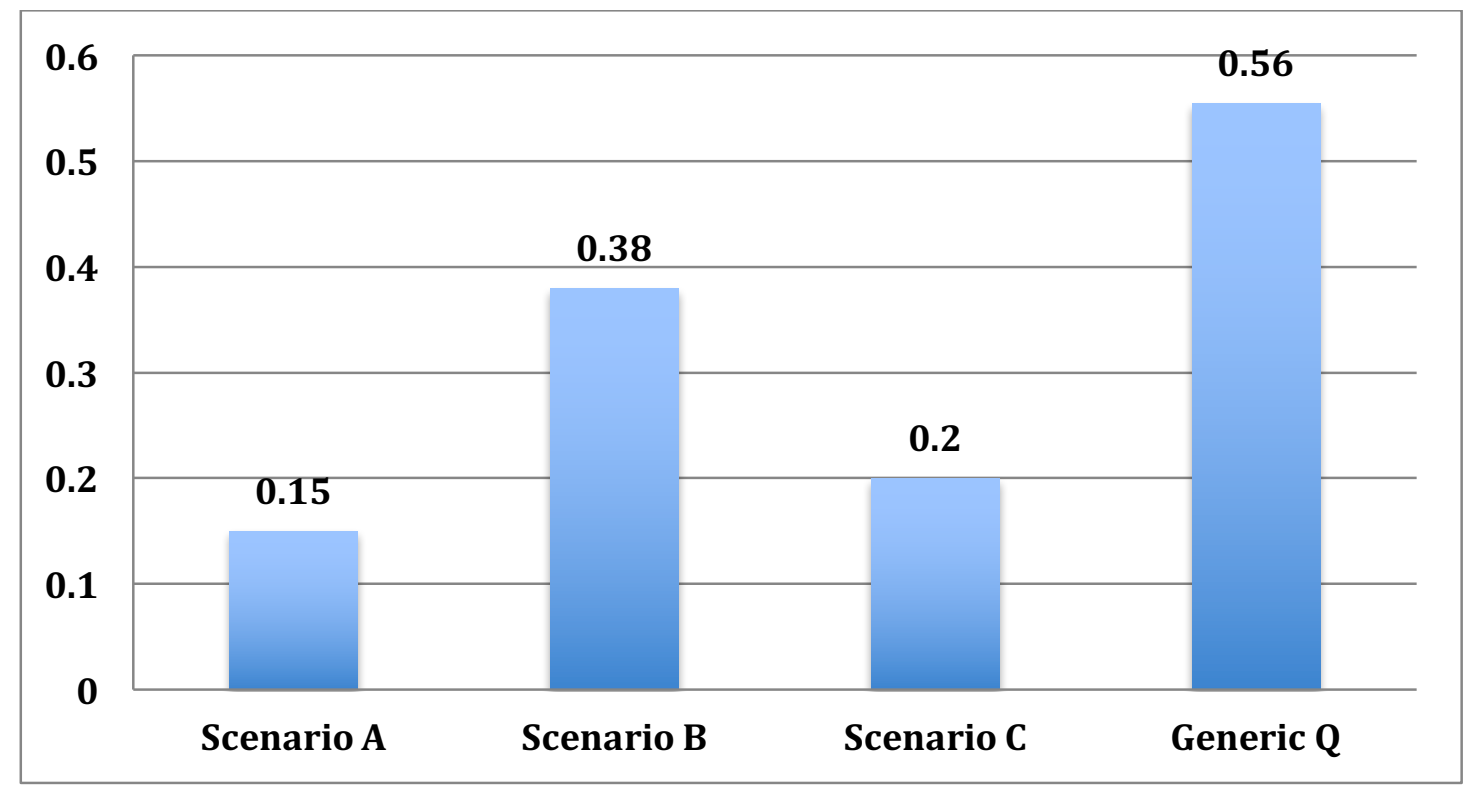

Figure 5: Overall Evaluation Scores - ME - Vitoria-Gasteiz

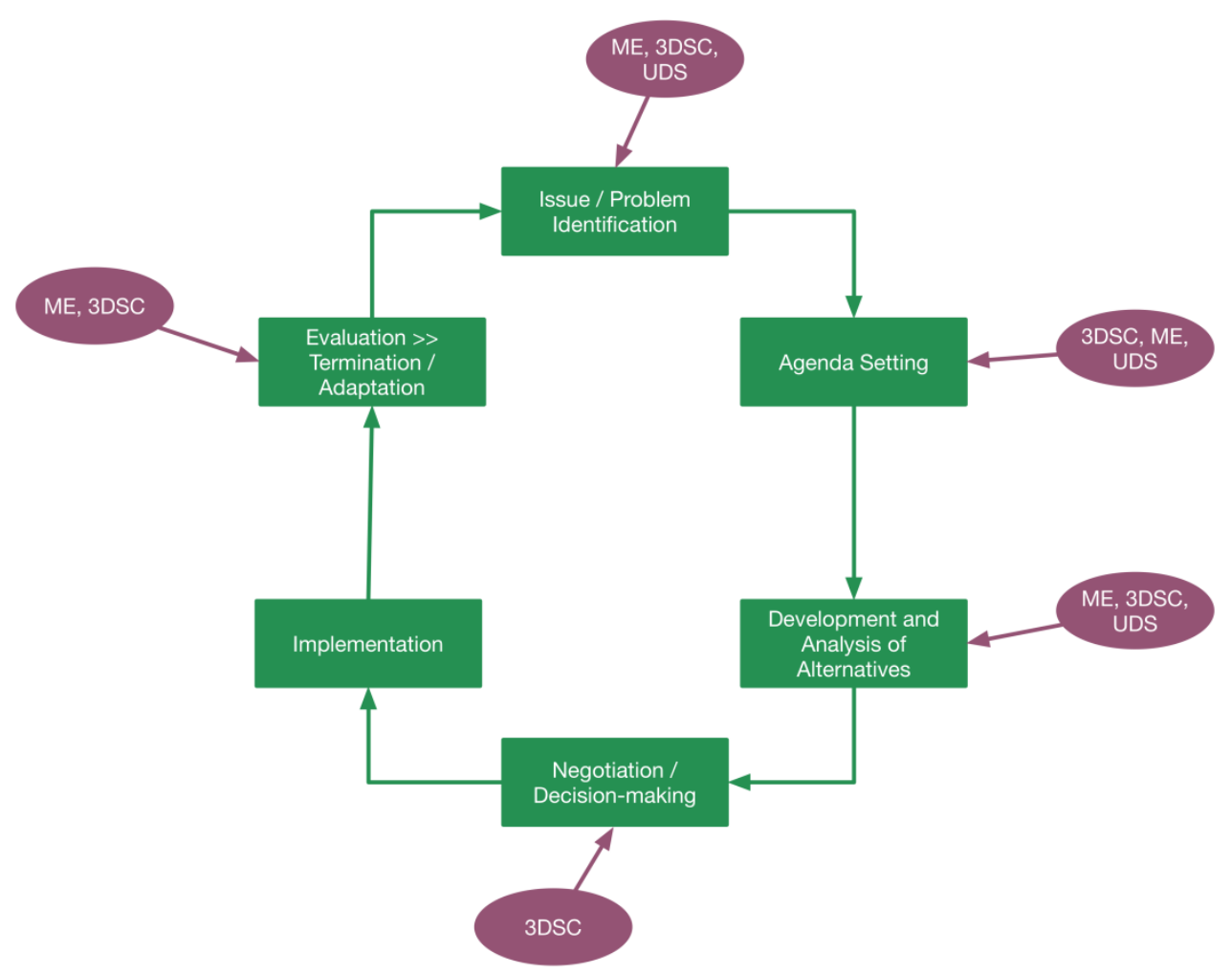

Figure 6: Generic Policy Model - Planning Policy Development (Khan, Ludlow, et al. 2014)

\section{Acknowledgements}

This project was partially funded under the EU FP7 programme and conducted in collaboration with Fraunhofer IGD, GeoVille, Vienna, Vitoria-Gasteiz, Bologna, Ruse, ASDE and The Austrian Institute of Technology (AIT). 
